\title{
Corrigendum: Correlated activity supports efficient cortical processing
}

\author{
Chou P. Hung ${ }^{1,2 *}$, Ding Cui ${ }^{1}$, Yueh-peng Chen ${ }^{2}$, Chia-pei Lin ${ }^{2}$ and Matthew R. Levine ${ }^{1}$ \\ ${ }^{1}$ Department of Neuroscience, Georgetown University, Washington, DC, USA \\ 2 Institute of Neuroscience, National Yang-Ming University, Taipei, Taiwan \\ *Correspondence: ch486@georgetown.edu
}

Edited and reviewed by:

Hans P. Op De Beeck, University of Leuven (KU Leuven), Belgium

Keywords: object recognition, inferior temporal cortex, macaque, visual search, efficient coding

\section{A corrigendum on}

Correlated activity supports efficient cortical processing

by Hung, C. P., Cui, D., Chen, Y.-p., Lin, C.-p., and Levine, M. R. (2014).

Front. Comput. Neurosci. 8:171. doi: 10.3389/fncom.2014.00171

In the original article, in the second paragraph of the Analyses section, there was a typo in the description of "soloists" that are based on the median 30\%ile. They are the $35-65 \%$ ile, not the $45-65 \%$ ile as previously reported. In addition to the 2 nd paragraph of the Analyses section, the typo also appears in 3 other places: Figure 2 legend, 1st paragraph of Results, and in the second paragraph of "Correlated Neurons are Mostly in Output Layers."

The authors apologize for this error.

Conflict of Interest Statement: The authors declare that the research was conducted in the absence of any commercial or financial relationships that could be construed as a potential conflict of interest.

Received: 05 February 2015; accepted: 09 February 2015; published online: 24 February 2015.
Citation: Hung CP, Cui D, Chen Y-p, Lin C-p and Levine MR (2015) Corrigendum: Correlated activity supports efficient cortical processing. Front. Comput. Neurosci. 9:25. doi: 10.3389/fncom.2015.00025

This article was submitted to the journal Frontiers in Computational Neuroscience.

Copyright (c) 2015 Hung, Cui, Chen, Lin and Levine. This is an open-access article distributed under the terms of the Creative Commons Attribution License (CC BY). The use, distribution or reproduction in other forums is permitted, provided the original author(s) or licensor are credited and that the original publication in this journal is cited, in accordance with accepted academic practice. No use, distribution or reproduction is permitted which does not comply with these terms. 